\title{
Analisis Maturity Level Business Goals 8 Menggunakan COBIT Pada PT. APLIN
}

\author{
${ }^{1}$ Awalludiyah Ambarwati, ${ }^{2}$ Ade Putra Habibi \\ ${ }^{1,2}$ Program Studi Sistem Informasi, Fakultas Ilmu Komputer, Universitas Narotama \\ ${ }^{1,2}$ Surabaya, Indonesia \\ E-mail: ${ }^{1}$ ambarwati1578@yahoo.com, ${ }^{2}$ presiden.habibi@gmail.com
}

Abstrak - PT. APLIN adalah salah satu perusahaan yang bergerak di bidang Information and Communication Technology (ICT) yang melayani berbagai kebutuhan pelanggan dalam hal komunikasi dan jaringan. Perkembangan TI (Teknologi Informasi) yang dinamis mengakibatkan adanya perubahan kebutuhan pelanggan. PT. APLIN memperbarui TI yang digunakan secara berkala dan berusaha memberikan layanan untuk memenuhi kebutuhan pelanggan. Penelitian ini dilakukan menggunakan framework COBIT 4.1 untuk mengetahui maturity level pada empat proses TI yaitu PO3 (Menentukan Arahan Teknologi), AI5 (Pengadaan Sumber Daya TI), DS2 (Mengelola Layanan Pihak Ketiga) dan DS6 (Mengidentifikasi dan Mengalokasikan Biaya). Dimana keempat proses TI tersebut merupakan bagian dari tujuan bisnis pencapaian optimasi biaya dari penyampaian layanan dalam perspektif pelanggan. Hasil penelitian menunjukan maturity level berada pada level Repeatable but Intuitive untuk proses TI PO3, DS2 dan DS6. Sedangkan proses TI AI5 berada pada level Defined. Mekanisme perencanaan pengadaan sumber daya TI dan perencanaan anggaran pada PT. APLIN sudah sesuai dan terdokumentasi dengan baik. Perusahaan perlu meningkatkan mekanisme pengembangan infrastuktur TI dan menjaga hubungan kinerja vendor atau pihak ketiga.

Keywords-Business Goal, COBIT 4.1, Maturity Level

\section{PENDAHULUAN}

PT. APLIN adalah perusahaan yang bergerak di bidang Information and Communication Technology (ICT) yang menyediakan kebutuhan komunikasi data pelanggan dalam bisnis skala kecil, menengah maupun besar. PT. APLIN menghubungkan berbagai usaha di Indonesia, menghadirkan komunikasi data, layanan informasi bisnis dan Internet hingga ke daerah-daerah terpencil. Perkembangan TI (Teknologi Informasi) yang dinamis mengakibatkan adanya 
perubahan kebutuhan pelanggan. Perusahaan membutuhkan panduan kejelasan arah perkembangan teknologi agar dapat memperbarui TI yang digunakan secara berkala guna memenuhi kebutuhan pelanggan melalui solusi tepat dan menyediakan dukungan sepanjang waktu.

Penerapan teknologi terbaru merupakan suatu investasi TI yang cukup besar. Investasi TI yang telah dilakukan seharusnya dapat dirasakan oleh pelanggan berupa layanan terbaik. Penelitian ini dilakukan menggunakan COBIT 4.1 untuk mengukur maturity level pada business goal 8 berupa Achieve cost optimisation of service delivery (pencapaian optimasi biaya dari penyampaian layanan). COBIT (Control Objective for Information and Related Technology) merupakan framework yang disusun oleh Information Technology Governance Institut (ITGI). COBIT 4.1 memiliki empat domain yaitu domain Plan And Organizer (PO), Acquire And Implement (AI), Delivery And Support (DS) dan Monitor and Evaluate (ME). Setiap domain memiliki IT Process [1].

\section{METODE PENELITIAN}

Tahapan penelitian pengukuran tingkat kematangan tujuan bisnis pencapaian optimasi biaya dari penyampaian layanan dalam perspektif pelanggan dapat dilihat pada Gambar 1. Penelitian ini terdiri dari empat tahap, yaitu tahap perencanaan, persiapan, pelaksanaan dan pembuatan laporan hasil penelitian. Tahap Perencanaan terdiri dari empat aktifitas. Diawali dengan melakukan studi pustaka COBIT 4.1 dan perspektif pelanggan dalam balance scorecard serta melakukan observasi berkaitan dengan kematangan tujuan bisnis pencapaian optimasi biaya dari penyampaian layanan pada PT. APLIN. Selanjutnya, melakukan identifikasi Proses Bisnis dan TI. Berikutnya, melakukan identifikasi Ruang Lingkup dan Tujuan yaitu pengukuran tingkat kematangan pencapaian optimasi biaya dari penyampaian layanan. Terakhir, menentukan metode yang akan digunakan berupa framework COBIT 4.1 untuk menghitung Maturity Level.

Tahap Persiapan memiliki tiga aktifitas. Pertama, menentukan tujuan bisnis dan IT Goals. Tujuan bisnis yang dipilih dalam penelitian ini adalah business goal 8 atau pencapaian optimasi biaya dari penyampaian layanan. Selanjutnya, melakukan pemetaan business goal (tujuan bisnis), IT Goals (Tujuan TI) dan IT Process (Proses TI) yang dapat dilihat pada Tabel 1, Tabel 2 dan Tabel 3. Untuk setiap IT Goals dipilih satu IT Process yang sesuai kebutuhan, sehingga diperoleh empat IT Process pada tiga domain yang dipergunakan, yaitu PO3 (Menentukan Arahan Teknologi), AI5 (Pengadaan Sumber Daya TI), DS2 (Mengelola Layanan Pihak Ketiga) dan DS6 
(Mengidentifikasi dan Mengalokasikan Biaya). Ketiga, pembuatan kuisioner berdasarkan Proses TI dari hasil pemetaan [2], [3].

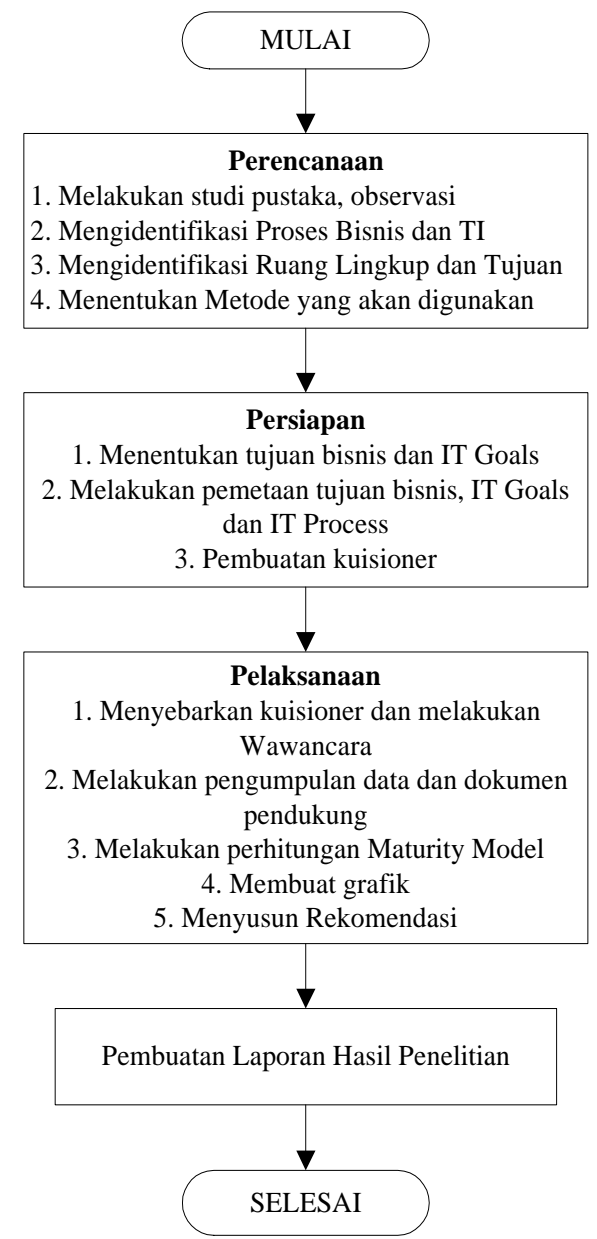

\section{Gambar 1. BAGAN ALIR TAHAPAN PENELITIAN}

Pembuatan kuesioner didasarkan pada IT Process yang telah dipilih. Responden diberi empat pilihan jawaban kualitatif yang terdapat pada Tabel 4. Nilai Kualitatif jawaban responden pada kuisioner (Gambar 2) dikonversi menjadi compliance value untuk penghitungan maturity level.

Tahap Pelaksanaan terdiri dari lima aktifitas. Pertama, menyebarkan kuisioner dan melakukan wawancara kepada responden. Penentuan responden dilakukan berdasarkan pemetaan Fungsi pada RACI Chart dengan Fungsi jabatan pada Struktur organisasi perusahaan. Tabel 6 menunjukan responden yang terlibat dalam penelitian ini yaitu Manajer Area, Asisten Manajer (Asman) Operasional, Asman FA (Finance and Administration), Engineer, Procurement, Kemitraan. 
Tabel 1. PemetaAn PerspeKTIF DAN TUJUAN BISNIS (BUSINESS GOAL) [1]

\begin{tabular}{|c|c|c|}
\hline Perpective & No. & Business Goals \\
\hline \multirow[t]{4}{*}{$\begin{array}{l}\text { Financial } \\
\text { Prespective }\end{array}$} & 1. & $\begin{array}{l}\text { Provide a good return on investment of IT-enabled } \\
\text { business investments }\end{array}$ \\
\hline & 2. & Manage IT-related business risk \\
\hline & 3. & Improve corporate govermance and transparency \\
\hline & 4. & Improve customer orientation and service \\
\hline \multirow{5}{*}{$\begin{array}{l}\text { Customer } \\
\text { Perspective }\end{array}$} & 5. & Offer competitive products and services \\
\hline & 6. & Establish service continuity and availability \\
\hline & 7. & $\begin{array}{l}\text { Create agility in responding to changing business } \\
\text { requirements }\end{array}$ \\
\hline & 8. & Achieve cost optimisation of service delivery \\
\hline & 9. & $\begin{array}{l}\text { Obtain reliable and useful information for strategic } \\
\text { decision making }\end{array}$ \\
\hline \multirow{6}{*}{$\begin{array}{l}\text { Internal } \\
\text { Perspective }\end{array}$} & 10. & Improve and maintain business process functionality \\
\hline & 11. & Lower process costs \\
\hline & 12. & $\begin{array}{l}\text { Provide compliance with external laws, regulations and } \\
\text { contracts. }\end{array}$ \\
\hline & 13. & Provide compliance with internal policies \\
\hline & 14. & Manage business change \\
\hline & 15. & Improve and Maintain operational and staff productivity \\
\hline \multirow{2}{*}{$\begin{array}{l}\text { Lerning and } \\
\text { Growth } \\
\text { Perspective }\end{array}$} & 16. & Manage product and business innovation \\
\hline & 17. & Acquire and maintain skilled and motivated people \\
\hline
\end{tabular}

Tabel 2. PemetaAn TuJuAn BISNIS DAN TUJUAn ti (IT GOALS) [1]

\begin{tabular}{|c|c|c|c|}
\hline Perpective & No. & Business Goals & IT Goals \\
\hline $\begin{array}{l}\text { Customer } \\
\text { Perspective }\end{array}$ & 8. & $\begin{array}{l}\text { Achieve cost optimisation of service } \\
\text { delivery }\end{array}$ & $\begin{array}{llll}7 & 8 & 10 & 24\end{array}$ \\
\hline
\end{tabular}

Tabel 3. PEMETAAN IT GOALS DAN IT PROCESS

\begin{tabular}{lll}
\hline \hline IT Goals & IT Process \\
\hline 7 & $\begin{array}{l}\text { Acquire and maintain integrated and standardised } \\
\text { application systems }\end{array}$ & PO3, AI2, AI5 \\
8 & $\begin{array}{l}\text { Acquire and maintain an integrated and standardised } \\
\text { IT infrastrucure }\end{array}$ & AI3, AI5 \\
10 & $\begin{array}{l}\text { Ensure mutual satisfaction of third-party relationship } \\
24\end{array}$ & DS2 \\
& $\begin{array}{l}\text { Improve IT's cost efficiency and its contribution to } \\
\text { business profitability }\end{array}$ & PO5, DS6 \\
\hline
\end{tabular}


Tabel 4. Nilai Pilihan JaWABan [2]

\begin{tabular}{lcll}
\hline \hline $\begin{array}{l}\text { Agreement with } \\
\text { Statement }\end{array}$ & $\begin{array}{l}\text { Compliance } \\
\text { Value }\end{array}$ & Nilai Kualitatif & Deskripsi \\
\hline Not at all & 0 & Kurang Setuju & Tidak ada sama sekali \\
A little & 0.33 & Cukup Setuju & Sedikit \\
Quite a lot & 0.66 & Setuju & Untuk tingkatan tertentu \\
Completely & 1 & Sangat Setuju & Lengkap \\
\hline
\end{tabular}

Identitas Responden:

\begin{tabular}{|l|l|l|l|}
\hline Nama & $:$ & & Tanda tangan \\
\hline Jabatan & $:$ & & \\
\hline Divisi / Unit & $:$ & & \\
\hline $\begin{array}{l}\text { Tanggal } \\
\text { pengisian }\end{array}$ & $:$ & & \\
\hline
\end{tabular}

\begin{tabular}{|l|l|l}
\hline Proses : Menentukan Pengembangan Teknologi (PO3) \\
\hline
\end{tabular}

\begin{tabular}{|c|c|c|c|c|c|}
\hline \multirow[b]{2}{*}{ No } & \multirow[b]{2}{*}{ Pertanyaan } & \multicolumn{4}{|c|}{ Pendapat } \\
\hline & & $\begin{array}{c}\text { Kurang } \\
\text { Setuju }\end{array}$ & $\begin{array}{l}\text { Cukup } \\
\text { Setuju }\end{array}$ & Setuju & $\begin{array}{l}\text { Sangat } \\
\text { Setuju }\end{array}$ \\
\hline 1. & $\begin{array}{l}\text { Perusahaan sadar akan } \\
\text { pentingnya pengembangan } \\
\text { infrastruktur teknologi di sentral } \\
\text { provider }\end{array}$ & & & & \\
\hline 2. & $\begin{array}{l}\text { Dalam setiap ada perubahan } \\
\text { teknologi hardware terbaru akan } \\
\text { mempengaruhi pengembangan } \\
\text { sentral provider }\end{array}$ & & & & \\
\hline 3. & $\begin{array}{l}\text { Setiap ada perubahan teknologi } \\
\text { software terbaru akan } \\
\text { mempengaruhi pengembangan } \\
\text { sentral provider }\end{array}$ & & & & \\
\hline 4. & Setiap adanya perubahan & & & & \\
\hline
\end{tabular}

Gambar 2. CONTOH KUISIONER UNTUK RESPONDEN

Tabel 5. DISKRIPSI RACI

\begin{tabular}{|c|c|c|}
\hline \multicolumn{2}{|c|}{ RACI } & Deskripsi \\
\hline$\overline{\mathrm{R}}$ & Responsible & Penanggungjawab, orang yang bertanggung jawab \\
\hline A & Accountable & $\begin{array}{l}\text { Pemilik kewenangan untuk menyetujui atau menerima } \\
\text { pelaksanaan suatu kegiatan }\end{array}$ \\
\hline $\mathrm{C}$ & Consulted & Pemberi konsultasi atau saran \\
\hline I & Informed & $\begin{array}{l}\text { Penerima informasi atau yang harus diberi informasi atau } \\
\text { yang harus mengetahui perkembangan dari suatu kegiatan } \\
\text { yang dilakukan }\end{array}$ \\
\hline
\end{tabular}


Tabel 6. DAFTAR RESPONDEN

\begin{tabular}{|c|c|c|}
\hline \multicolumn{2}{|c|}{ IT Process } & Responden \\
\hline $\mathrm{PO} 3$ & Menentukan Arahan Teknologi & $\begin{array}{l}\text { Manajer Area, Asman Operasional, } \\
\text { Engineer }\end{array}$ \\
\hline AI5 & Pengadaan Sumber Daya TI & $\begin{array}{l}\text { Manajer Area, Asman FA, } \\
\text { Procurement }\end{array}$ \\
\hline DS2 & Mengelola Layanan Pihak Ketiga & $\begin{array}{l}\text { Manajer Area, Asman Operasional, } \\
\text { Kemitraan dan Engineer }\end{array}$ \\
\hline DS6 & $\begin{array}{l}\text { Mengidentifikasi dan } \\
\text { Mengalokasikan Biaya }\end{array}$ & $\begin{array}{l}\text { Manajer Area, Procurement, Asman } \\
\text { Operasional, Engineer, Asman FA }\end{array}$ \\
\hline
\end{tabular}

Tabel 7. MATURITY LEVEL

\begin{tabular}{|c|c|c|}
\hline Level & Keterangan & Penjelasan \\
\hline 0 & Non-existent & $\begin{array}{l}\text { Perusahaan tidak mengetahui sama sekali proses } \\
\text { teknologi informasi diperusahaannya }\end{array}$ \\
\hline 1 & Initial / Ad Hoc & $\begin{array}{l}\text { Terdapat bukti bahwa perusahaan mengetahui adanya } \\
\text { hal-hal yangperlu diperhatikan. Namun demikian } \\
\text { belum ada standarisasi proses, pendekatan dilakukan } \\
\text { secara individual atau berdasarkan kasus. Pendekatan } \\
\text { secara keseluruhan belum diorganisasikan dengan baik. }\end{array}$ \\
\hline 2 & $\begin{array}{l}\text { Repeatable but } \\
\text { Intuitive }\end{array}$ & $\begin{array}{l}\text { Proses telah dikembangkan dengan adanya prosedur } \\
\text { yang sama dan digunakan oleh banyak orang dalam } \\
\text { menyelesaikan tugas. Belum ada standarisasi prosedur } \\
\text { untuk pelatihan secara formal ataupun komunikasi dan } \\
\text { tangung jawab bergantung pada individu. Tingkat } \\
\text { kepercayaan pada kemampuan individu sangat tinggi, } \\
\text { sehingga kesalahan yang sama sering kali terjadi. }\end{array}$ \\
\hline 3 & Defined Process & $\begin{array}{l}\text { Terdapat standarisasi prosedur dan telah } \\
\text { didokumentasikan serta dikomunikasikan melalui } \\
\text { pelatihan. Proses wajib ditaati sesuai standar. } \\
\text { Penyimpangan sulit dideteksi. Prosedur yang } \\
\text { digunakan belum canggih tetapi diformulasikan pada } \\
\text { praktek. }\end{array}$ \\
\hline 4 & $\begin{array}{l}\text { Managed and } \\
\text { Measurable }\end{array}$ & $\begin{array}{l}\text { Manajemen memonitor dan mengukur kepatuhan } \\
\text { dengan prosedur dan mengambil tindakan terhadap } \\
\text { proses yang tampaknya tidak dapat bekerja secara } \\
\text { efektif. Proses berada di bawah peningkatan konstan } \\
\text { dan memberikan latihan yang baik. Otomatisasi dan } \\
\text { peralatan digunakan secara terbatas atau terfragmentasi }\end{array}$ \\
\hline 5 & Optimised & $\begin{array}{l}\text { Proses telah disempurnakan ke tingkat praktek yang } \\
\text { baik, berdasarkan hasil dari perbaikan berkelanjutan } \\
\text { dan model maturity dari perusahaan lain. TI digunakan } \\
\text { secara terintegrasi untuk mengotomatisasi alur kerja, } \\
\text { menyediakan alat-alat untuk meningkatkan kualitas } \\
\text { dan efektivitas, membuat perusahaan cepat beradaptasi. }\end{array}$ \\
\hline
\end{tabular}


Kemudian melakukan pengumpulan data dan dokumen pendukung berupa profil dari perusahaan, kebijakan dan SOP (Standard Operating Procedure) yang digunakan. Selanjutnya, melakukan perhitungan Maturity Level [2], [3]. Dimana Maturity Model merupakan alat bantu untuk mengetahui tingkat kematangan IT Process yang terdiri dari enam level, yang dapat dilihat pada Tabel 7, mulai Level 0 hingga Level 5 [1]. Keempat, membuat grafik berupa spider chart. Terakhir menyusun rekomendasi. Tahap terakhir dari penelitian ini adalah pembuatan laporan hasil penelitian sebagai dokumentasi.

\section{HASIL DAN PEMBAHASAN}

Seluruh pegawai PT. APLIN yang menjadi responden (Tabel 6) sangat kooperatif dalam mengisi kuisioner sehingga semua kuisioner yang disebarkan kembali seluruhnya dalam keadaan terisi. Kuisioner yang telah diisi responden tersebut kemudian ditabulasikan untuk mendapatkan nilai compliance (Tabel 8). Kemudian dilakukan normalisasi nilai compliance (Tabel 9) dilanjutkan dengan menghitung maturity level (Tabel 10). Nilai maturity untuk empat IT Process yang dianalisis disajikan pada Tabel 11.

Tabel 8. Perhitungan Nilai COMPLIANCE PADA PO3

\begin{tabular}{cccc}
\hline \hline Level & $\begin{array}{c}\text { Nilai Compliance } \\
(\mathbf{A})\end{array}$ & $\begin{array}{c}\text { Jumlah } \\
\text { Pernyataan (B) }\end{array}$ & $\begin{array}{c}\text { Tingkat Compliance } \\
(\mathbf{A} / \mathbf{B})\end{array}$ \\
\hline 0 & 0,77 & 1 & 0,77 \\
1 & 2,21 & 3 & 0,74 \\
2 & 2,55 & 3 & 0,85 \\
3 & 1,77 & 3 & 0,59 \\
4 & 1,98 & 3 & 0,66 \\
5 & 1,43 & 2 & 0,72 \\
\hline
\end{tabular}

Tabel 9. NORMALISASI NILAI COMPLIANCE PADA PO3

\begin{tabular}{ccc}
\hline Level & $\begin{array}{c}\text { Nilai Compliance } \\
\text { (A) }\end{array}$ & $\begin{array}{c}\text { Normalisasi } \\
\text { (A/Total) }\end{array}$ \\
\hline 0 & 0,77 & 0,18 \\
1 & 0,74 & 0,17 \\
2 & 0,85 & 0,20 \\
3 & 0,59 & 0,14 \\
4 & 0,66 & 0,15 \\
5 & 0,72 & 0,17 \\
Total & $\mathbf{4 , 3 2}$ & \\
\hline
\end{tabular}


Tabel 10. Perhitungan Nilai Maturity LeVel Pada IT Process PO3

\begin{tabular}{ccc}
\hline \hline Level (A) & Normalisasi (B) & Kontribusi (A*B) \\
\hline 0 & 0,18 & 0,00 \\
1 & 0,17 & 0,17 \\
2 & 0,20 & 0,39 \\
3 & 0,14 & 0,41 \\
4 & 0,15 & 0,61 \\
5 & 0,17 & 0,83 \\
& Total Maturity Level & $\mathbf{2 , 4 1}$ \\
\hline
\end{tabular}

Tabel 11. NILAI MATURITY LEVEL

\begin{tabular}{lll}
\hline \hline IT Process & $\begin{array}{l}\text { Nilai } \\
\text { Maturity }\end{array}$ \\
\hline PO3 & Menentukan Arahan Teknologi & 2,41 \\
AI5 & Pengadaan Sumber Daya TI & 2,52 \\
DS2 & Mengelola Layanan Pihak Ketiga & 2,39 \\
DS6 & Mengidentifikasi dan Mengalokasikan Biaya & 2,49 \\
\hline
\end{tabular}

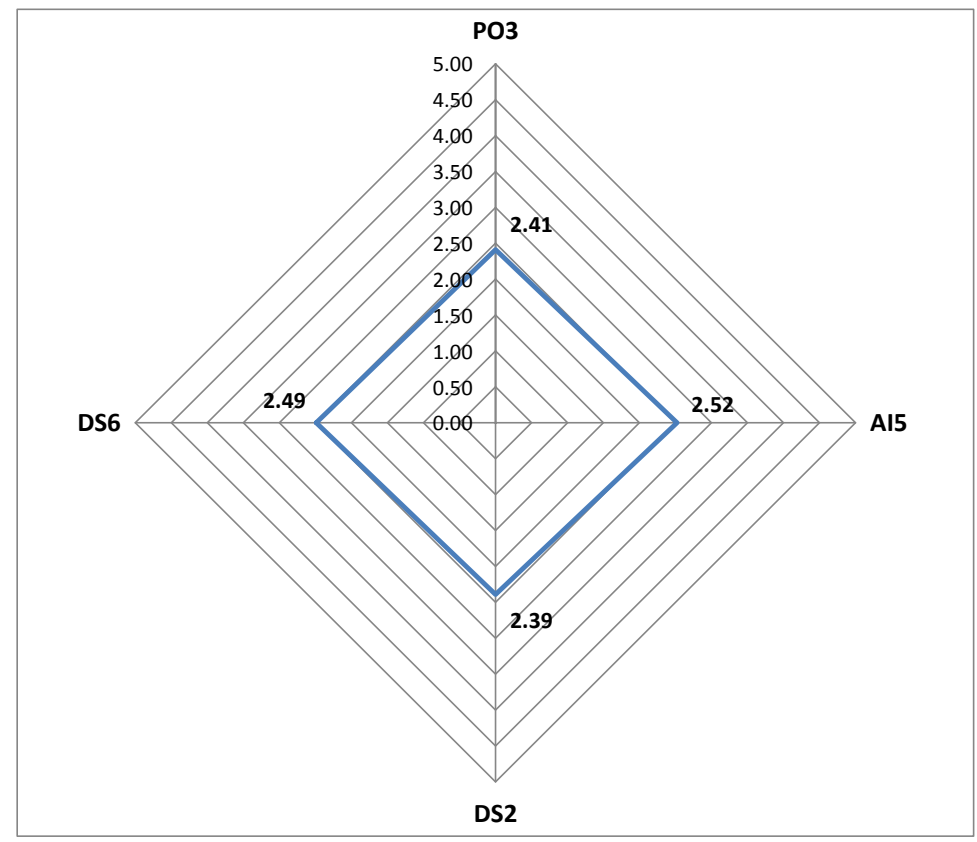

Gambar 3. SPIDER CHART NILAI MATURITY LEVEL 
Jurnal INTENSIF, Vol.1 No.2 Agustus 2017

ISSN: 2580-409X (Cetak) / 2549-6824 (Online)

Rekomendasi pada empat IT Process diberikan untuk perbaikan dan peningkatan. Hal ini dilakukan agar terjadi peningkatan nilai pada pengukuran maturity level berikutnya. Rekomendasi untuk PO3 (Menentukan Arahan Teknologi) berupa pembuatan SOP untuk memperjelas alur kerja dan pembagian tugas antar karyawan. Membuat regulasi internal terkait penyalahgunaan aplikasi atau sanksi atas pelanggaran yang mungkin dilakukan user dalam pengembangan infrastruktur teknologi.

Rekomendasi untuk IT Process AI5 (Pengadaan Sumber Daya TI) adalah mengoptimalkan penggunaan sistem informasi pengadaan barang mulai dari proses tender sampai dengan laporan pengadaan barang. Meniadakan proses pengadaan barang secara manual. Menjaga hubungan kerja dengan vendor dan memberikan sangsi apabila vendor melakukan pelanggaran saat pengadaan barang.

IT Process DS2 (Mengelola Layanan Pihak Ketiga) direkomendasikan untuk menunjuk salah satu karyawan yang bertanggung jawab untuk melakukan quality control. Membuat sistem informasi manajemen yang mengelola semua rekanan perusahaan. Rekomendasi IT Process DS6 (Mengidentifikasi dan Mengalokasian Anggaran) berupa sosialisasi pada jajaran manajemen menengah ke atas terhadap informasi dan tanggung jawab manajemen anggaran. Melaporkan penggunaan biaya langsung dan tidak langsung tepat waktu.

\section{KESIMPULAN DAN SARAN}

Hasil analisis pencapaian optimasi biaya dari penyampaian layanan menggunakan COBIT 4.1 pada PT. APLIN diperoleh nilai maturity level 2,41 untuk IT Process PO3 dan 2,39 untuk IT Process DS2 serta nilai maturity level 2,49 untuk IT Process DS6 yang dikategorikakan pada level Repeatable but Intuitive. Sedangkan IT Process AI5 memperoleh nilai maturity level 2,52 yang dikategorikan pada level Defined. Dengan demikian dapat disimpulkan bahwa mekanisme perencanaan pengadaan barang kebutuhan TI telah terdokumentasi dengan baik. Sedangkan perencanaan anggaran, mekanisme pengembangan infrastuktur teknologi informasi dan menjaga hubungan kinerja vendor masih perlu ditingkatkan.

PT. APLIN disarankan melakukan perbaikan diantaranya berupa pembuatan strategi TI dan SOP untuk memperjelas alur kerja dan pembagian tugas antar karyawan. Membuat regulasi internal terkait penyalahgunaan aplikasi atau sanksi atas pelanggaran yang mungkin dilakukan user dalam pengembangan infrastruktur teknologi. Selain itu juga mengoptimalkan penggunaan sistem informasi pengadaan barang mulai dari proses tender sampai dengan laporan pengadaan 
barang. Menjaga hubungan kinerja dengan vendor dan memberlakukan sangsi apabila vendor melakukan pelanggaran saat pengadaan barang. Melakukan monitoring dan evaluasi biaya untuk meminimalkan penyimpangan anggaran.

\section{Daftar Pustaka}

[1] Information Technology Governance Institut, 2007, COBIT 4.1: Framework Control Objective, Management Guidelines, Maturity Models, IT Governance Institut, Rolling Meadows.

[2] Pederiva, Andrea, 2003, The COBIT Maturity Model in a Vendor Evaluation Case. Information Systems Control Journal, Vol 3, Information Systems Audit and Control Association

[3] Rozas, Indri Sudanawati., 2012, Model Perhitungan Tingkat Kedewasaan TI (Maturity Level) Menggunakan Framework COBIT 4.1, Prosiding Seminar Nasional Teknik Informatika (SANTIKA 2012) Teknik Informatika-Fakultas Teknologi Industri Universitas Pembangunan Nasional "Veteran" Jawa Timur, 10 Maret 2012. pp 73-77, ISSN 2252-3081

[4] Sarno, Riyanarto, 2009, Strategi Sukses Bisnis dengan Teknologi Informasi Berbasis Balanced Scorecard dan Cobit, ITS Press, Surabaya. 